\title{
Pragmatic evaluation of the Toyota Production System (TPS) analysis procedure for problem solving with entry-level nurses
}

\author{
Lukasz M. Mazur ${ }^{1}$; Shi-Jie (Gary) Chen ${ }^{2}$; Barbara Prescott ${ }^{3}$ \\ ${ }^{1}$ North Carolina State University (USA); ${ }^{2}$ Northern Illinois University (USA); ${ }^{3}$ Montana State \\ University (USA) \\ lukaszmazun@ncsu.edu; gchen@,ceet.niu.edu; bprescott@montana.edu
}

Received August 2008

Accepted November 2008

\begin{abstract}
Medication errors occurring in hospitals are a growing national concern. These medication errors and their related costs (or wastes) are seen as major factors leading to increased patient safety risks and increased waste in the hospital setting. This article presents a study in which sixteen entry-level nurses utilized a Toyota Production System (TPS) analysis procedure to solve medication delivery problems at one community hospital. The objective of this research was to study and evaluate the TPS analysis procedure for problem solving with entry-level nurses. Personal journals, focus group discussions, and a survey study were used to collect data about entry-level nurses' perceptions of using the TPS problem solving approach to study medication delivery. A regression analysis was used to identify characteristics that enhance problem solving efforts. In addition, propositions for effective problem solving by entry-level nurses to aid in the reduction of medication errors in healthcare delivery settings are offered.
\end{abstract}

Keywords: medication errors, problem solving, nurses, analysis, improvement, Toyota Production System

\section{Introduction}

In 1999 the report by Institute of Medicine suggested that the hospitals in the United States have "major problems" in terms of management and control of Pragmatic Evaluation of the Toyota Production System (TPS) Analysis Procedure for Problem 240 Solving with Entry-level Nurses 
medication delivery errors (IOM, 1999). Despite tremendous efforts to reduce medication errors since the 1999 report by IOM, the medication error rates remain unacceptable (National Patient Safety Foundation, 2004; IOM, 2006). A report by IOM (2006) suggested that medication errors became so common in hospitals that patients should expect to suffer at least one error every day they remain hospitalized. As a result, it was estimated that medication-related errors harm approximately 1.5 million people in the United States, costing the nation at least $\$ 3.5$ billion annually. Clearly, gaps exist in the knowledge required to understand and reduce the medication errors and the related costs.

To deal with the problems, recently, few healthcare organizations have responded by using Toyota Production System (TPS) (also called "lean") approach to help solve their process related problems (IOM, 2005). TPS principles and tools have been used in many applications to achieve major improvements in the quality, efficiency, safety, and/or customer-centered processes, products, and services in a wide range of manufacturing and service industries. However, the healthcare sector as a whole has been very slow to embrace lean principles and tools, even though they have shown to yield valuable returns to the small but growing number of healthcare organizations and clinicians that have applied them (Thompson, Wolf, \& Spear, 2003; Spear 2005; Jimmerson, Weber \& Sobek, 2005; Sobek \& Jimmerson, 2003, 2004, 2006; Mazur \& Chen, 2007, 2008a,b). In addition, despite the enormous potential, the inefficient uses of lean principles and tools by healthcare professionals could lead the organization's management to premature and negative conclusions about their fit into healthcare environment. There are ample cases documenting that poorly used industrial engineering techniques for improvement, like total Quality Management (TQM) or Six Sigma, actually generated additional work for the professionals and very little apparent reward (Hackman \& Wageman, 1995; Zbaracki, 1998; Hug \& Martin, 2000; Repenning \& Sterman, 2002; Linderman, Scroeder, Zaheer, \& Choo, 2003). The ability to effectively analyze and solve medication delivery problems is absolutely critical to healthcare industry. Therefore, the objective of this research is to study and evaluate the TPS analysis procedure for problem solving with entry-level nurses. The researchers adapted Toyota's analysis procedure for problem solving and developed a three-page template called "Map to Improve" (M2I) tool that combines Value Stream Mapping (VSM) and problem solving A3 report. 


\section{Background information}

\subsection{Current challenges for problem solving in Healthcare}

According to TPS philosophy, when faced with medication error, healthcare professionals should scientifically and jointly investigate the system to find and remove the root causes to prevent error recurrence. However, the literature reports the lack of time for problem solving, psychological issues with error reporting and improvement, and dominance of short-term approaches to address problems in the healthcare industry (Edmondson, 1999; Uribe, Schweikhart, Pathak, Dow, \& Marsh, 2002; Tucker \& Edmondson, 2002, 2003). Tucker and Edmonson (2002), one of the leading researchers in the field of healthcare process improvement, suggested that nurses are likely to engage in improvement efforts if managers are physically present on the nursing floor, have a reputation for "safety" and "improvement" and have the time needed to devote to problem solving efforts. Such managerial presence and support often can increase the feeling of "gratification" and at the same time prevent the feelings of "burnout" in frontline healthcare professionals. Edmondson (1999) showed that psychological safety enables willingness to engage in "second-order problem solving" behavior because improvement efforts are inherently risky and can have negative consequences for the person who raises the concerns. Second-order problem solving behavior occurs when the worker, in addition to patching the problem so that the immediate task at hand can be completed, also takes action to address underlying causes. Second-order problem solving also includes: communicating to the person or department responsible for the problem; bringing it to managers' attention; sharing ideas about what caused the situation and how to prevent recurrence with someone in a position to implement changes; implementing changes; and verifying that changes have the desired effect (Tucker \& Edmondson, 2002). In addition, being associated with problems and change efforts can result in damage to one's reputation (Dutton, 1993). Therefore, workers will be more likely to engage in improvement efforts if they feel they have some protection from such backlash (Edmondson, 1999). Nembharth and Edmondson (2006) showed that leader inclusiveness - words and actions exhibited by leaders that invite and appreciate others' contributions - can help healthcare people and teams overcome the inhibiting effects of psychological safety, allowing members to collaborate in process improvement. Reversely, McFadden and colleagues $(2006 a, b)$ showed that 
lack of top management support, lack of resources, lack of incentives and lack of knowledge can significantly hinder the implementation of any improvement strategies. A computer simulation model (Anderson, Ramanujam, Hensel, Anderson, \& Sirio, 2006) that has been developed to explore organizational changes required to improve patient safety based on a medication error reporting system predicted that the number of medication errors reported by hospital staff would increase over time. The simulation model also found that organizational actions needed to reduce the risks of future errors occurred less than $46 \%$ of the time and found that $96 \%$ of the actions taken in response to reported errors involved individual staff. However, organizational actions that only affect individual staff are likely to have little effect in reducing future errors (Anderson et al., 2006). Organizational or system changes could result in sustaining changes in the organization culture and practices if implemented properly (Anderson et al., 2006).

\subsection{Toyota Production System (TPS) analysis procedure for problem solving}

The Toyota Production System is perhaps the most powerful model devised to-date for efficient design and management of business operations (Jimmerson, Weber, \& Sobek, 2005). This system helped thrust Toyota Motor Corporation from a small truck-maker struggling in the wake of World War II, to the world's leading automaker by the end of the 2000's. Many Japanese manufacturers clichéd Toyota's production system, or TPS, and after several decades of refinement it has became the trademark of the "Japanese approach" to manufacturing (Monden, 1993). US researchers who studied and documented this approach nicknamed it lean manufacturing because of its ability to do so much more with fewer resources than traditional approaches. Some describe lean manufacturing as a philosophy, a perspective that abhors waste in any form, relentlessly strives to eliminate defects, and continually attacks both in a never-ending pursuit of perfection (Ohno, 1988, Shingo 1989; Monden, 1993).

However, it seems unlikely that TPS principles could transfer to hospital environment with equal success as in manufacturing. Therefore, there is a need to study and evaluate the impact of Toyota's problem solving approach in healthcare. At the high level, Toyota's problem solving approach can be seen as a scientific approach: Plan, Do, Check, and Act (often called PDCA). The concept of the PDCA Cycle was originally developed by Walter Shewhart, the revolutionary statistician 
who developed statistical process control in the Bell Laboratories in the U.S. during the 1930s. It is often referred to as the Shewhart Cycle. It was taken up and promoted very effectively from the 1950 s by the famous Quality Management authority, W. Edwards Deming, and is consequently known by many as the Deming Wheel. The PDCA Cycle consists of four stages that the investigator must go through to get from 'problem faced' to 'problem solved'. In summary, at each stage the investigator performs the following activities:

- Stage 1: Plan to improve your operations by identifying the problems and come up with ideas for solving these problems

- Stage 2: Do changes that are designed to solve the problems on a small or experimental scale

- Stage 3: Check whether the experimental changes are achieving the desired result or not

- Stage 4: Act to implement changes on a larger scale if the experiment is successful

If the experiment was not successful, skip the Act stage and go back to the Plan stage to come up with some new ideas for solving the problem and go through the cycle again. Plan-Do-Check-Act describes the overall stages of improvement activities, but how is each stage carried out? According to Deming, PDCA should be repeatedly implemented to increase knowledge of the undertaken with each cycle bringing the investigator closer to the ultimate goal (Deming, 1986). Such approach is based on the belief that the investigator's knowledge and skills are limited, but improved with each iteration. With the improved knowledge at each iteration, the investigator may choose to refine or alter the ultimate goal.

Specifically, at the operational level, TPS analysis procedure to problem solving is equipped with two basic tools, namely Value Stream Mapping (VSM) and A3 problem solving tool (Jimmerson et al., 2005). Value stream maps graphically represent the key people, material and information flows required to deliver a product or service. They are designed to distinguish value-adding versus and nonvalue-adding steps (Jimmerson et al., 2005). As a problem solving method used by Toyota, the term "A3" derives from the paper size used for the report, which is the metric equivalent to $11^{\prime \prime} \times 17^{\prime \prime}$ paper. Toyota actually uses several styles of A3 
reports for solving problems, for reporting project status, and for proposing policy changes, with each having its own design (Sobek \& Jimmerson, 2006). The A3 problem solving tool includes the following nine essential steps (Sobek and Jimmerson, 2004):

- Step 1: Observe the current process

- Step 2: Draw a diagram to represent the current process

- Step 3: Determine the root causes to the problem by asking the "5 Whys"

- Step 4: Develop the countermeasures to address the root causes to the problem

- Step 5: Draw a diagram of the envisioned (or target) process based on consensus with the affected parties

- Step 6: Plan the implementation

- Step 7: Discuss all of the above with the affected parties

- Step 8: Implement the actions planned

- Step 9: Collect the follow-up data on the outcome of the new process and comparing against pre-specified targets

In general, steps 1 through 7 refer to "Plan", step 8 refers to "Do", and step 9 refers to "Check" of the PDCA cycle. The "Act" stage is the creation of new organizational work routines when they are proved worthy in step 9. These nine steps provide an approximate order for TPS analysis procedure for problem solving.

\section{Map-to-Improve (M2I) tool}

The M2I tool was adapted from Toyota's 9-step analysis procedure for problem solving (Mazur, 2008). It combines Value Stream Mapping (VSM) and problem solving report (called also A3 report) into one template. Figure 1 presents the M2I method (in a compacted format) with the following 9-step systems analysis procedure: 1 ) identify problem area; 2) describe the problem; 3) draw diagram or flowchart of current state map where problem exists; 4) describe why the current system is wrong (not ideal) to cause the problem; 5) describe what needs to be 
done to fix the problem; 6) describe when it needs to be done; 7) describe who is responsible (key team players and/or key departments); 8) draw diagram or flowchart of future state map (targeted system) that will solve the problem; and 9) describe project success measurement plan. Similarly to A3 tool, steps 1 through 7 refer to "Plan", step 8 refers to "Do", and step 9 refers to "Check" of the PDCA cycle. The "Act" stage is the creation of new organizational work routines when they are proved worthy in step 9. In addition, M2I incorporates one more block to provide the date, addressing party, and the tool user. For this project, the entrylevel nurses learned to collect data and present the following systems characteristics in the current and future state map for every studied task:

- Batch Size: The operational size for a standard batch under which the task was expected to be performed with respect to the current process and procedure. The batch size per task is measured by two distribution functions: 1) uniform (U) with two parameters (minimum batch size and maximum batch size); and 2) triangular ( $T$ ) with three parameters (minimum batch size, average batch size, and maximum batch size)

- Cycle Time (CT): The operational time for one unit and/or one standard batch size under which the task is expected to be performed. The cycle time per task is measured by two distribution functions: 1 ) uniform (U) with two parameters (minimum cycle time and maximum cycle time); and 2) triangular $(T)$ with three parameters (minimum cycle time, average cycle time, and maximum cycle time)

- Human Resources (HR): The official name of the human resource (i.e., RN, LPN, Unit Clerk, etc.) working on the task the task

- Availability (A): The procedural time that is assigned for the specific task. The availability time represents how long the task is expected to take 


\begin{tabular}{|l|}
\hline Project Title (What are we trying to do?): \\
\hline Short Project Description (Concept/ Purpose/lmportance): \\
\hline Diagram (flowchart) of Current System: \\
\hline What about the system is wrong (not IDEAL)?: \\
\hline What needs to be done to fix problems (root causes)?: \\
\hline -IF NOT SURE: PROVDE IDEAS \\
\hline When it is needed to be done?: \\
\hline IF NOT SURE: PROVIDE IDEAS \\
\hline Who is responsible (key team "players"; key departments involved)? \\
\hline "IF NOT SURE: PROVIDE IDEAS \\
\hline Project SUccess Measurement Plan: \\
\hline Diagram (flowchart) of Future (targeted) System: \\
\hline \multicolumn{1}{|c|}{ Future Conditions } \\
\hline
\end{tabular}

Figure 1. "Map to Improve (M2I)".

\section{Research design and method}

The study was performed at one community hospital $(\mathrm{CH})$ with 89 inpatient beds during September, October, November, and December 2007. Sixteen entry-level nurses who were seniors in their last semester of a Bachelor of Science in Nursing program volunteered to participate in this research study. Each participant completed a consent form. One of the two university clinical instructors participated on the research team. The research team used a 'Qual-Quan' model, also known as the exploratory mixed method design approach to conducting this research (Gay, Geoffrey, \& Airasian 2006; Driscoll, Appiah-Yeboah, Salib, Rupert, 2007). Qualitative data was first collected using unstructured conversation session and focus groups to explore the subject under investigation and come up with explicit study variables for the survey instrument. This part of the research method was also supported by literature reviews on problem solving (Anzai \& Simon, 1979; Staver, 1986; Goldstein \& Levin, 1987; Sobek \& Jimmerson, 2004, 2006). Second, 
the quantitative approach was used to analyze the data from the survey study to identify characteristics that enhance problem solving efforts.

\subsection{Data Collection}

First, all study participants learned how to use the M2I tool to analyze the medication delivery system. The study participants (entry-level nurses) were prompted to analyze the entire process to identify the direct effects of the true root causes of medication errors. Once the participants gained an understanding of how the tasks currently were done within the system and developed a grasp of the root cause(s) of the medication errors using the current state map, they were ready to consider how the system can be improved. The goal of the future state map was to address the root cause(s) while utilizing the principles of technology, process, and human factors influencing task performance. The future map is a diagram of how the proposed system could work with the improvements in place. The main idea is to move the system closer to an ideal state in order to provide for the customer (patient) needs. Throughout the study, data were collected using electronic student journals/notes. The entry-level nurses used a journal to document their individual activities/behaviors related to medication delivery improvements over time. The main shortcoming of this method was incomplete written records. However, to offset this deficiency, the research team conducted weekly focus group meetings with the participants. The conversation sessions allowed the researchers to collect more in-depth data to further understand "how" and "why" of some of the analysis and improvement steps were accomplished. At any time during the study, the participants were allowed to consult with the research team regarding any encountered problems with respect to the project. Upon completion of the project, the research team conducted a survey study using the instrument presented in Figure 2. The survey instrument contained one positively and one reversed negatively worded close-ended questions for every predictor variable under study. In designing the instrument, the research team followed the guidelines provided by the literature (Aiman-Smith \& Markham, 2004; Alreck \& Settle, 2004). The survey instrument was kept short to maximize the rate of response without diluting the survey objectives. The survey instrument was administered to the participants with a cover letter. The cover letter explained to the participants that this survey was voluntary, and they were free to stop at any time. For unknown reasons, one entry-level nurse decided not to participate in survey studies. 
Based on the literature review on cognitive problem solving, problem solving using the TPS approach (Anzai \& Simon, 1979; Staver, 1986; Goldstein \& Levin, 1987; Sobek \& Jimmerson, 2004, 2006) and the qualitative analysis of data gathered from unstructured conversations and focus groups with entry-level students, the following predictor, criterion, and control variables were established.

Predictor variables include:

- Memorizing via organized documentation (Q1-Q2): the ability to remember information such as words, numbers, pictures, and procedures about the studied medication delivery problem

- Distilling and grouping information via drawing system map(s) (Q3-Q4): the ability to combine/arrange different pieces of information about the work processes

- Brainstorming via visualization (Q5-Q6): the ability to understand about the root-cause(s) of the medication delivery problem

- Recognizing root-cause(s) of the problem via linking the process flow with task(s) characteristics (Q7-Q8): the ability to recognize the true rootcause(s) of the medication delivery problem

- Generating creative improvement ideas via experimentation by drawing/redrawing system $\operatorname{map}(\mathrm{s})(\mathrm{Q} 9-\mathrm{Q} 10)$ : the ability to generate ideas to solve the root-cause(s) of the medication delivery problem

- Communication via visual representation (Q11-Q12): the ability to facilitate communication with others via visual representation

- Systems thinking via visualization (Q13-Q14): the ability to facilitate the improvement planning via visual representation

- Selecting the improvement measures via linking the process flow with task(s) characteristics (Q15-Q16): the ability to select/develop the indicators to measure improvement with respect to the root-cause(s) of the medication delivery problem 


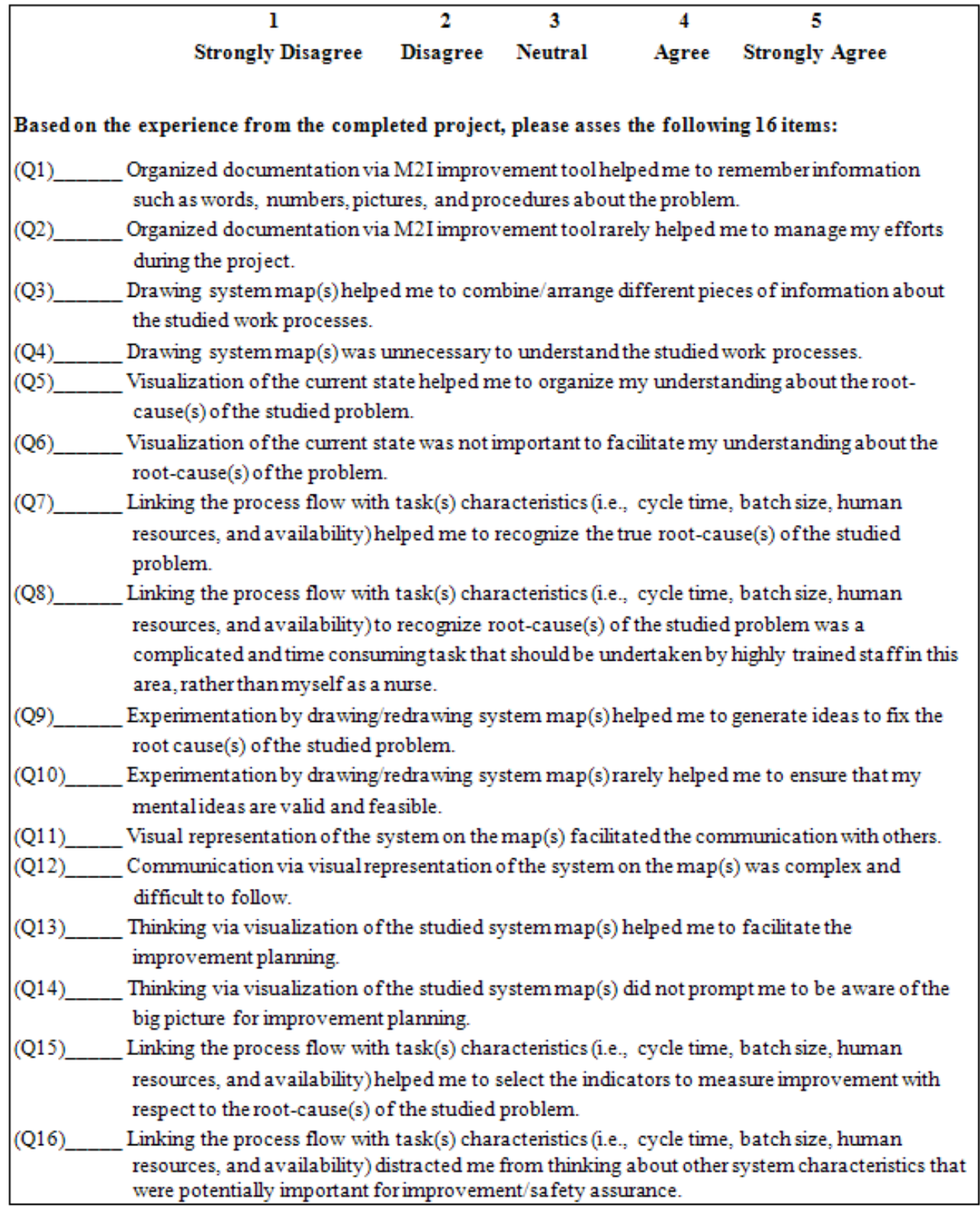

Figure 2. "Survey Instrument".

The participants were asked to evaluate each survey question using a 5-point Likert scale (1932) (from $1=$ strongly disagree to $5=$ strongly agree). For each completed survey, the scores from both questions under each predictor variable were added and averaged to arrive at a composite score for each prediction variable.

Data collection was completed using the evaluation of the criterion and control variables. 
- Process improvement (criterion variable): process improvement (PI) is defined as the improvement in various process parameters (productivity, wasted time, number of errors, costs, and patient care) as a result of problem solving, as reported by the nursing students. The research team reviewed all submitted M2I improvement reports from participants after three months of data collection. Each report was assessed using a 5-point Likert scale $(5 \mathrm{pt}=$ Very Good, 4 pts $=$ Good, 3pts Average, 2 pts Poor, 1 pts Very Poor) based on the binary decisions (answer to questions 1 to 5: Yes = $1 \mathrm{pt}$; No = 0pt) based on the quality of their proposed solutions in terms of five evaluation points:

1). Was the problem clearly defined?

2). Were the objectives met based on the identified major problems?

3). Were the proposed improvement actions feasible?

4). Were the implementation plans feasible?

5). Were the improvement measurement plans feasible?

Evaluation points were assigned to each completed M2I report by the research team with the collaboration of the quality improvement professional at $\mathrm{CH}$ who is responsible for medication error reporting and improvements. Standardized evaluation helped the research team control assessment of the process improvement. The final analysis was done by adding up the scores from four evaluation points to get a composite score for the criterion variable - process improvement.

- Following the TPS analysis procedure for problem solving (control variable): M2I requires executing certain key steps in the problem solving process. This control variable was used to investigate the potential effect it may have on the relationship between the predictor and criterion variables in process improvement. The authors assessed the control variable using a 5-point Likert scale (from 1 = strongly disagree to $5=$ strongly agree) based on the binary decisions on whether entry-level nurses followed all 10 input boxes in the M2I tool shown in Figures 1 (Were M2I boxes filled? Yes $=0.25 \mathrm{pt}$, No $=$ Opt) as well as filling the boxes correctly (was the content correct? Yes = 
$0.25 \mathrm{pt}$, No $=0 \mathrm{pt})$. The final score was derived by adding up the scores from the binary decisions to get a composite score for the control variable.

At Toyota, the philosophy is to relentlessly pursue corporate-wide problem solving that leads to process improvement (Spear, 2005). In addition, at Toyota, problem solvers always follow the scientific method of PDCA cycle with a 9-step procedure imbedded into A3 tool. Such approach encouraged problem solvers to share skills with each other and to develop new processes. This leads to process improvement and creation of new routines, which promotes acquisition of new knowledge and skills by organizational members, and helps develop and refine core competencies not easily imitable by competitors (Lei, Hitt, \& Bettis, 1996). In summary, problem solving based on scientific method is critical to maintaining a competitive advantage in a turbulent and chaotic healthcare industry. This corroborates the usefulness of our control and criterion variables in this research method.

\subsection{Completed M2I Tool: Illustrative Example}

In general, the project included identifying, analyzing and suggesting improvements for a specific problem with medication delivery at the $\mathrm{CH}$ using the TPS analysis procedure for problem solving as outlined in the M2I tool. The entrylevel nurses were able to observe and interact with the medication delivery processes and also interacted with $\mathrm{CH}$ professionals during the three-month period of their clinical experience at $\mathrm{CH}$. All inpatient departments including the Medical unit, Surgical unit, Intensive Care Unit (ICU), and Emergency Department (ED) were selected for data collection. Each participant completed one improvement using M2I tool. To illustrate the completed M2I tool, Figures $3 a$ to $3 c$ present an overview of a M2I tool prepared by one of the participants. In summary, this entrylevel nurse identified and proposed solution to the "traffic" problem at the medication dispensing machine. In the proposed solution the "non-time specific" medications, or in other words, medications that do not need to be delivered to patient at a specific time, should not be dispensed by nurses during the "heavytraffic" times to allow higher throughput. 


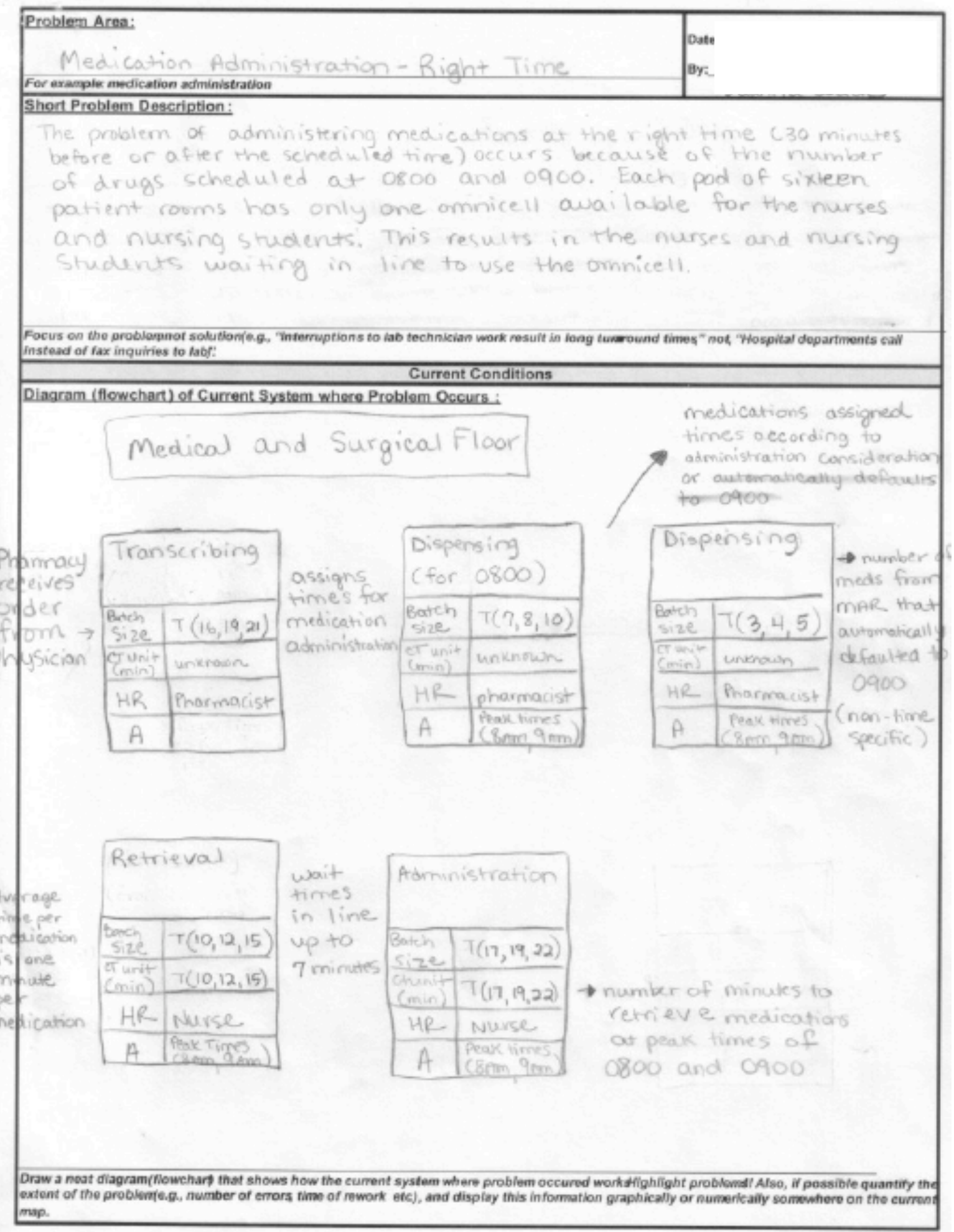

Figure 3a. "Example of Completed Map to Improve (M2I)". 


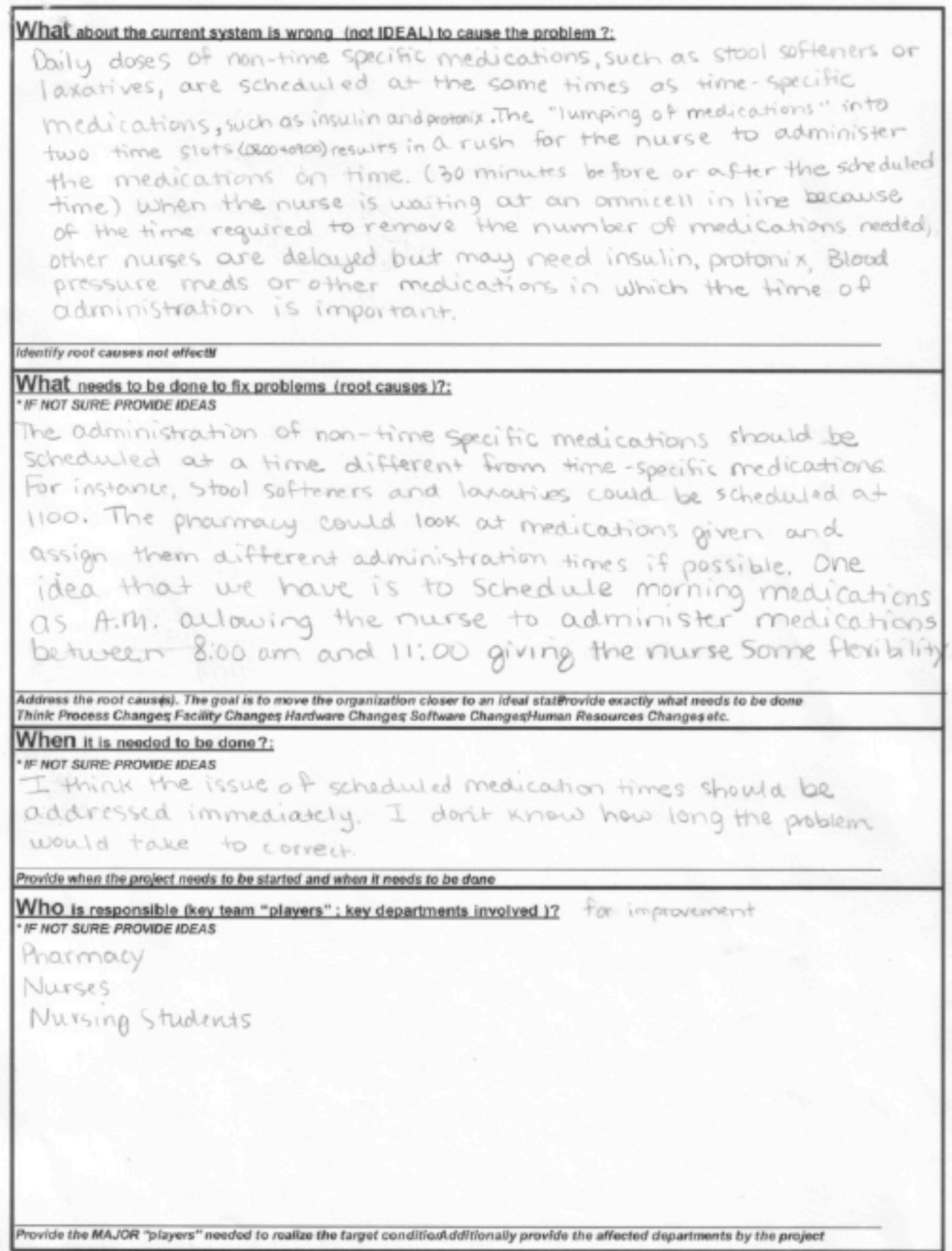

Figure 3b. "Example of Completed Map to Improve (M2I)". 


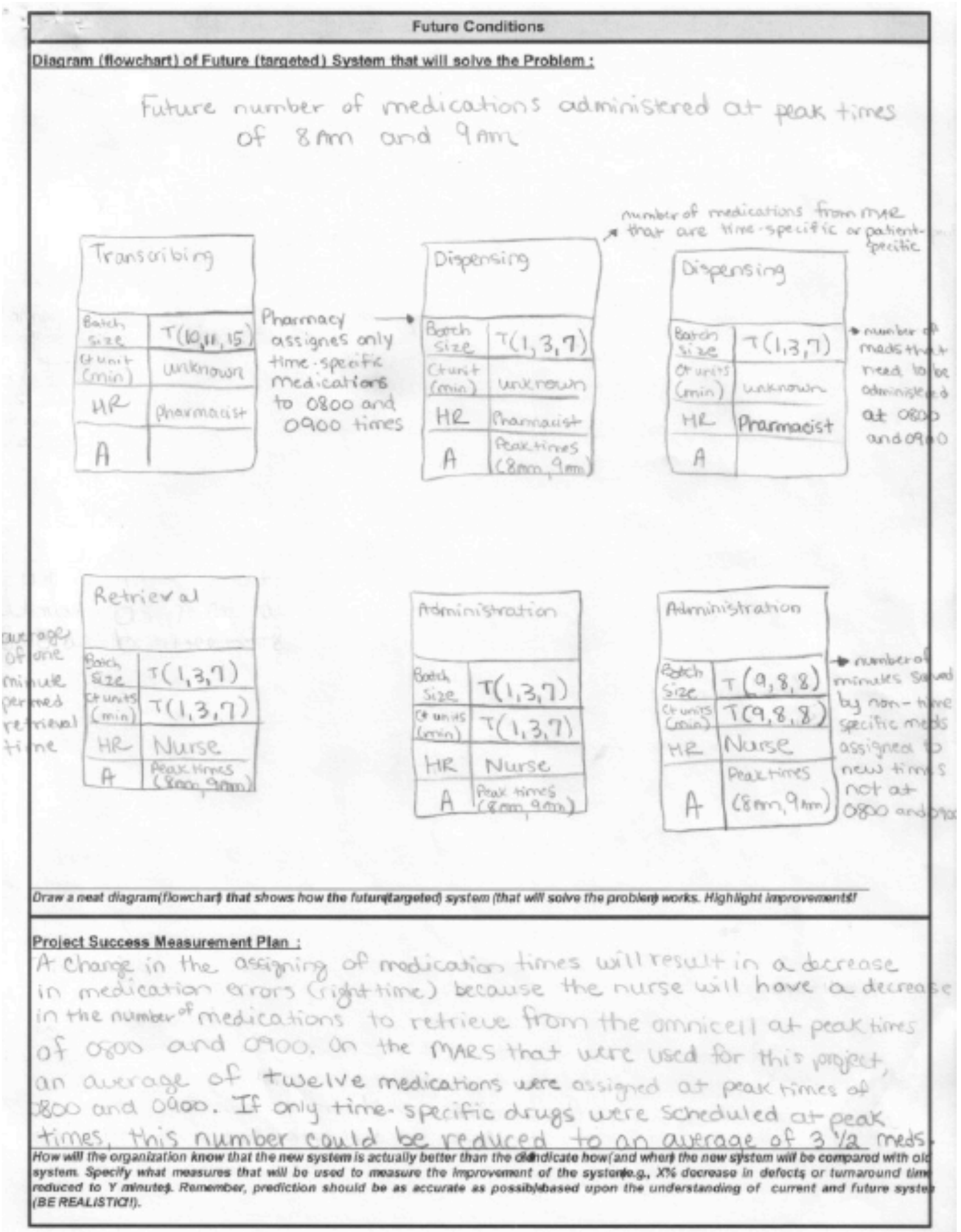

Figure 3c. "Example of Completed Map to Improve (M2I)". 


\section{Data analysis and results}

In this study, the M2I tool was used to study and evaluate the TPS analysis procedure to solve problems while being used by entry-level nurses. Table 1 represents the statistical summary of the predictor, control and criterion variables. With the recommendations by Garsen (2002) for qualitative research with a relatively small sample size and subjectivity due to personal opinions/feelings, the significance level of 0.1 was set. Based on Anderson-Darling test for normality, the evidence suggested that all variables were normally distributed. Next the reliability measure of a psychometric instrument was calculated using Cronbach's alpha for each set of questions under every testable predictor variable in the survey. All Cronbach's alpha results fell between 0.6 and 0.95, an acceptable range to ensure reliability (or internal consistency) of the survey questions (Robinson, Shaver, \& Wrightsman, 1991).

\begin{tabular}{|c|c|c|}
\hline Predictor & A-D p-value & Cronbach's alpha \\
\hline Q1-Q2 & $<.005$ & 0.85 \\
\hline Q3-Q4 & 0.08 & 0.61 \\
\hline Q5-Q6 & $<.005$ & 0.90 \\
\hline Q7-Q8 & 0.03 & 0.81 \\
\hline Q9-Q10 & 0.02 & 0.93 \\
\hline Q11-Q12 & 0.06 & 0.83 \\
\hline Q13-Q14 & $<.005$ & 0.84 \\
\hline Q15-Q16 & 0.01 & 0.91 \\
\hline Control & 0.03 & N/A \\
\hline Criterion & 0.1 & N/A \\
\hline
\end{tabular}

Table 1. "Summary of the Nurses Responses to Survey Questions".

Table 2 represents bivariate correlations, means, and standard deviations for the predictor, control and criterion variables. All correlations between predictor variables were below 0.75 , the level commonly considered as problematic in qualitative research (Masson \& Perreault, 1991; Pelled, Eisenhardt, \& Xin, 1999). The evidence suggests that the criterion variable is positively correlated with the predictor variable Q1 - Q2 (memorizing via organized documentation) $(r=0.78, \mathrm{p}$ $<0.00)$ and control variable (following the M2I process) $(r=0.82, p<0.00)$ and negative correlated with Q5 - Q6 (brainstorming via visualization) ( $r=-0.45, \mathrm{p}=$ 0.09). The rest of the correlations between predictor variables and the criterion variable can be considered as neutral. The same pattern of correlations, however 
with slightly different $r$-values, can be found between the control variable and predictor variables.

\begin{tabular}{|c|c|c|c|c|c|c|c|c|c|c|}
\hline & $\begin{array}{l}\text { Q1 } \\
\text { Q2 } \\
\end{array}$ & $\begin{array}{l}\text { Q3 } \\
\text { Q4 } \\
\end{array}$ & $\begin{array}{l}\text { Q5 } \\
\text { Q6 } \\
\end{array}$ & $\begin{array}{l}\text { Q7 } \\
\text { Q8 } \\
\end{array}$ & $\begin{array}{c}\text { Q9 } \\
\text { Q10 } \\
\end{array}$ & $\begin{array}{l}\text { Q11 } \\
\text { Q12 } \\
\end{array}$ & $\begin{array}{l}\text { Q13 } \\
\text { Q14 } \\
\end{array}$ & $\begin{array}{l}\text { Q15 } \\
\text { Q16 } \\
\end{array}$ & $\mathbf{C t}$ & $\mathrm{Cr}$ \\
\hline \multirow[t]{2}{*}{ Q3 - Q4 } & 0.62 & & & & & & & & & \\
\hline & 0.01 & & & & & & & & & \\
\hline \multirow[t]{2}{*}{ Q5 - Q6 } & -0.23 & 0.15 & & & & & & & & \\
\hline & 0.41 & 0.61 & & & & & & & & \\
\hline \multirow[t]{2}{*}{ Q7 - Q8 } & 0.21 & 0.31 & 0.28 & & & & & & & \\
\hline & 0.45 & 0.26 & 0.32 & & & & & & & \\
\hline \multirow[t]{2}{*}{ Q9 - Q10 } & 0.42 & 0.61 & 0.27 & 0.33 & & & & & & \\
\hline & 0.12 & 0.02 & 0.34 & 0.23 & & & & & & \\
\hline \multirow[t]{2}{*}{ Q11 - Q12 } & 0.31 & 0.69 & 0.11 & 0.33 & 0.70 & & & & & \\
\hline & 0.27 & 0.00 & 0.69 & 0.24 & 0.00 & & & & & \\
\hline \multirow[t]{2}{*}{ Q13 - Q14 } & 0.54 & 0.73 & -0.26 & 0.27 & 0.35 & 0.60 & & & & \\
\hline & 0.04 & 0.00 & 0.34 & 0.33 & 0.20 & 0.02 & & & & \\
\hline \multirow[t]{2}{*}{ Q15 - Q16 } & 0.28 & 0.44 & 0.32 & 0.48 & 0.41 & 0.12 & 0.28 & & & \\
\hline & 0.32 & 0.10 & 0.24 & 0.07 & 0.13 & 0.68 & 0.31 & & & \\
\hline \multirow[t]{2}{*}{$\begin{array}{l}\text { Control } \\
\text { (Ct) }\end{array}$} & 0.82 & 0.44 & -0.40 & 0.05 & 0.03 & 0.04 & 0.54 & 0.19 & & \\
\hline & 0.00 & 0.10 & 0.14 & 0.86 & 0.92 & 0.90 & 0.04 & 0.51 & & \\
\hline \multirow[t]{2}{*}{$\begin{array}{l}\text { Criterion } \\
(\mathrm{Cr})\end{array}$} & 0.78 & 0.35 & -0.45 & 0.03 & -0.04 & 0.00 & 0.46 & 0.13 & 0.92 & \\
\hline & 0.00 & 0.20 & 0.09 & 0.91 & 0.88 & 0.99 & 0.09 & 0.65 & 0.00 & \\
\hline Mean & 2.83 & 2.83 & 2.90 & 2.10 & 2.20 & 2.73 & 2.93 & 2.43 & 3.87 & 3.82 \\
\hline S.D. & 0.79 & 1.10 & 0.78 & 0.95 & 0.96 & 0.90 & 0.73 & 0.68 & 1.06 & 1.0 \\
\hline
\end{tabular}

Table 2. "Summary of Correlations, Means and Standard Deviations for Study Variables".

Table 3 represents the results of multiple regression analysis. The results indicate that only Q1 - Q2 (memorizing via organized documentation) is a significant predictor of process improvement $(\mathrm{t}=3.17, \mathrm{p}=0.019)$. ANOVA calculations presented in Table 4 shows that regression model is significant ( $F$-value $=3.31, p$ $=0.081)$. The remaining predictor variables did not show a significant relationship with the criterion variable $(p>0.1)$. The normal probability plots, the fitted values 
plots, and the ordered plots of residuals indicated no concerns with respect to the adequacy of the models.

\begin{tabular}{|l|r|r|r|r|}
\hline \multicolumn{5}{|c|}{ Regression Model } \\
\hline \multicolumn{1}{|c|}{ Predictor } & Coef & \multicolumn{1}{c|}{ SE Coef } & \multicolumn{1}{c|}{ T } & \multicolumn{1}{c|}{ P } \\
\hline Constant & 0.78 & 2.37 & 0.33 & 0.75 \\
\hline Q1 - Q2 & 1.28 & 0.40 & 3.17 & $* 0.019$ \\
\hline Q3 - Q4 & -0.16 & 0.57 & -0.29 & 0.79 \\
\hline Q5 - Q6 & -0.10 & 0.43 & -0.23 & 0.82 \\
\hline Q7 - Q8 & -0.08 & 0.27 & -0.29 & 0.78 \\
\hline Q9 - Q10 & -0.48 & 0.37 & -1.30 & 0.24 \\
\hline Q11 - Q12 & 0.01 & 0.45 & 0.03 & 0.98 \\
\hline Q13 - Q14 & 0.32 & 0.71 & 0.45 & 0.67 \\
\hline Q15 - Q16 & 0.18 & 0.43 & 0.42 & 0.69 \\
\hline
\end{tabular}

Note: * p-value $<0.1$

$S=0.730 R-S q=0.815 R-S q(A d j)=0.561$

Table 3. "Summary of Coefficient Analysis"

\begin{tabular}{|l|c|c|c|c|c|}
\hline \multicolumn{7}{|c|}{ ANOVA } \\
\hline \multicolumn{1}{|c|}{ Source } & DF & SS & MS & F & P \\
\hline Regression & 8 & 14.135 & 1.767 & 3.310 & 0.081 \\
\hline Residual Error & 6 & 3.199 & 0.533 & & \\
\hline Total & 14 & 17.333 & & & \\
\hline
\end{tabular}

Table 4. "Analysis of Variance for Regression Model"

\section{Discussion}

The objective of this research is to study and evaluate the TPS analysis procedure for problem solving with entry-level nurses. The results from correlation analysis suggested that the study participants perceived the TPS analysis procedure for problem solving imbedded into M2I tool as helpful in remembering information such as words, numbers, pictures, and procedures about the studied problem (Q1 - Q2 with $r=0.78, p<0.00)$. In addition, the participants found the TPS analysis procedure was useful facilitating the improvement planning process via visual representation (Q13 - Q14 with $r=0.46, p=0.09)$. Also, the control variable (following the TPS analysis procedure for problem solving) was found to be correlated with process improvement $(r=0.92, p<0.00)$. Surprisingly, the entrylevel nurses indicated that the brainstorming via visualization of current state map(s) does not facilitate the understanding about the root-cause(s) of the problem (Q5 - Q6 with $r=-0.45, \mathrm{p}=0.09)$. From our correlation analysis, the 
evidence suggests that entry-level nurses perceived certain predictor variables as positive $(+)$ and some as negative $(-)$. These results are presented in the form of the following propositions:

- Proposition $1(+)$ : Organized documentation increases entry-level nurses' abilities to better analyze medication delivery problems.

- Proposition $2(+)$ : Systems thinking about medication delivery via visualization increases entry-level nurses' abilities to develop relevant improvement planning suggestions.

- Proposition $3(-)$ : Brainstorming via visualization does not facilitate the entry-level nurses' abilities to understand the root-cause(s) of the medication delivery problem.

The propositions, which are grounded in statistical analysis, suggest that medication delivery problem solving is more effective if the entry-level nurses are able to document the work in an organized fashion from the beginning. Second, the visualization of medication delivery systems under study allows the entry-level nurses to conceptualize medication delivery processes at the system level, and thus better develop an improvement plan for the identified problems. Third, counter intuitively, the entry level nurses indicated that brainstorming via visualization did not facilitate the individual' abilities to understand the rootcause(s) of medication delivery problems. The research team also measured the effectiveness of TPS analysis procedure for problem solving in terms of process improvements and analyzed the data using multiple regression model. The results suggested that only the memorization via organized documentation (Q1 - Q2) was perceived by the entry-level nurses as helpful during process improvement $(t=$ $3.17, p=0.019)$. To some degree this corroborates the usefulness of the TPS analysis procedure for problem solving. From the weekly focus group sessions, electronic journals and M2I reports, the research team learned that most rootcauses of medication delivery problems reported by the entry-level nurses were grounded in qualitative phenomena like vigilance/compliance, psychological safety, productivity pressures, and/or cultural barriers. Such phenomena are rather hard to be represented and analyzed graphically via mapping. Therefore, despite the success in problem solving while using M2I tool, the survey responses indicate that the "return on efforts/investment" devoted by entry-level nurses to 
drawing/redrawing the system map(s), linking/analyzing the process characteristics, and/or communication via visual representation seemed neutral. Such findings highlight an opportunity for a future research to discover the characteristics of effective process mapping in healthcare industry.

Researchers examining TPS analysis procedure for problem solving in healthcare industry found that they may be effective in improving work processes (Spear, 2005; Sobek \& Jimmerson, 2003, 2004; 2006, Jimmerson, Weber \& Sobek, 2005; Ghosh \& Sobek, 2006; Mazur \& Chen, 2008a,b). Sobek \& Jimmerson (2004, 2006) further tested Toyota's A3 Report for process improvement and found the A3 Report to be an objective tool that promotes joined communication and behavioral change towards a common purpose in improving organizational work processes. Ghosh and Sobek (2006) also proposed three characteristics for effective problem solving while using A3 Report: 1) need for validation of current system knowledge against reality; 2) need for joint problem solving by affected parties; and 3) need for joint validation of new knowledge. Such characteristics have been detected in hospitals that utilized "clinical microsystems" for organizational learning and delivery of care (Mohr, Batalden, \& Barach, 2004). Gosh and Sobek (2006) also suggests that problem solvers rarely get to the root cause of the problem due to inadequate shared understanding of the work, coupled with individualistic behavior. Mazur and Chen (2008b), while piloting TPS principles at a community hospital, found that "highly" autonomous culture combined with "loosely" defined workflow procedures are often the main causes of individualistic behaviors that could lead to errors. Finally, Reason (2004), argued that errors could be thwarted at the last minute if those on the frontline had acquired some degree of "error wisdom" based on vigilance and technical skills to recognize and deal with potential errors.

\section{Limitations}

The following obstacles were identified. First, this study was conducted in one organizational. Second, data collection using direct observation by entry-level nurses presented several difficulties: 1 ) direct observation has been shown to alter behavior (also known as Hawthorne effect), particularly motivating subjects to perform at higher levels than they would if unobserved (Burke, McKee, Wilson, Donahue, \& Batenhorst, 2000); 2). the fact that the entry-level nurses had limited experience in hospital settings possibly hindered their abilities to understand some 
of the events witnessed; and 3) the unknown bias of the researchers, which could influence what was recorded, coded and analyzed, could be present in this research (Miles \& Huberman, 1994). Third, the study did not have a control group. Comparing the results between the intervention groups and the control groups (i.e., nursing students performing improvement projects without using the M2I method) would have given more credibility to the research outcomes. Fourth, only one particular instrument, the M2I method, was used. However, research in the area of engineering design shows that visual representations (i.e., current and future state maps) influence cognition of the creator's ideas and decisions (Bodker, 1998; Lewis, 2006). In addition, representations may be good or poor (Johnson, 1998) and many different forms of representation exist, each potentially containing only certain or limited information needed to fully understand the studied system (Peschl \& Stary, 1998). Fifth, this study used a specific set of performance measures focusing on the project outcomes. Future work should focus on using multiple instruments and multiple measures (i.e., increased satisfaction, increased knowledge, etc.) for determining the effects of an intervention on nursing students. Using such multiple instruments and measures will provide more robust results and protect against potential interpretive errors. Sixth, another shortcoming of this research was the small sample size of nursing students, which was due to the fact that the research took place at one community hospital with 16 senior nursing students available. A larger sample size, perhaps representing different populations (i.e., different genders, ethnic groups, etc.), would have given more statistical power to the survey data and results. It is important to mention that mixed method designs for exploring complex research objectives, like the one in this paper, can still provide a deep understanding of survey responses via qualitative analysis of data, and provide detailed assessment of patterns of responses via statistical analysis. Due to the limitations including sample size, this research provides a set of propositions that are grounded in statistical analysis which do not represent cause-and-effect relationships. Furthermore, because the mixed method research is time consuming it often leads researchers working under tight budget and time constraints to reduce sample size or limit the time spent in the field. Seventh, the survey study was administered at one point in time, meaning that the survey study was cross-sectional. Therefore, establishing definitive causal relationships among the study variables was not possible. The results would have had more validity if a longitudinal survey design was used with the survey data collection replicated at multiple points in time. Finally, this study was conducted in 
the inpatient hospital areas. Future research should also investigate the possibility of applying industrial engineering methods/tools in the areas of outpatient. Therefore, based on the limitations of this study, generalization of the findings to the entire population of entry-level nurses cannot be ascertained.

\section{Conclusions}

The challenge is to manage the growing knowledge of healthcare systems improvement and ensure that future healthcare providers will have the abilities and skills needed to utilize an industrial engineering approach to analyze and improve healthcare delivery (IOM, 2005). The ability to analyze medication delivery problems is absolutely critical to the healthcare industry. However, healthcare systems analysis and the resulting improvements performed by healthcare professionals are not well understood. This research outlines some of the characteristics needed for effective problem solving efforts. In addition, propositions for effective problem solving by entry-level nurses to aid in the reduction of medication errors in healthcare delivery settings are proposed. The research team hopes that the proposed insights into these areas will result in improved strategies for professional development of healthcare providers. If TPS tools and practices are independently transformed to healthcare industry without the in-depth understanding about how healthcare professionals and improve their healthcare medication delivery systems, then they will likely impose an unnatural collaboration process and result in unsatisfactory solutions. For example, with the emerging knowledge, nursing schools would consider close collaboration with industrial engineering schools to incorporating systems engineering methods/tools into their educational curriculum. The practical implication of this research extends to the development of better methods/tools for healthcare delivery improvements. It is essential that improvement strategies be developed to enhance a natural collaboration process between healthcare disciplines. In summary, once entry-level nurses and other healthcare professionals are provided with the educational training for industrial engineering methods, the effort and the performance behind medication delivery improvement in all healthcare settings can be greatly increased. Therefore patient risk as well as systems waste can be decreased. 


\section{Acknowledgments}

We would like to thank all participating entry-level nurses for their diligent work in collecting and analyzing data. Without their professionalism and expertise, this research could not be accomplished.

\section{References}

Alreck, P.L., \& Settle, R.B. (2004). The survey research handbook. New York: McGraw-Hill/Irwin.

Aiman-Smith, L., \& Markham, S.K. (2004). What you should know about using surveys. Research Technology Management, 47(3), 12-15.

Anderson, J.G., Ramanujam, R., Hensel, D., Anderson, M.M, \& Sirio, C.A. (2006). The need for organizational change in patient safety. International Journal of Medical Informatics. 75, 809-817.

Anzai, K., and Simon, H.A. (1979). The theory of learning by doing. Psychological Review 86, 124-140.

Bodker, S. (1998). Understanding representation in design. Human Computer Interaction, 13, 107-125.

Burke, T.A., McKee, J.R., Wilson, H.C., Donahue, R.M.J., Batenhorst, A.S., et al. (2000). A comparison of time-and-motion and self-reporting methods of work measurement. Journal of Nursing Administration, 30(3), 118-125.

Deming, W.E. (1986). Out of the Crisis. Cambridge, Mass: Massachusetts Institute of Technology, Center for Advanced Engineering Study.

Driscoll, D.L., Appiah-Yeboah, A., Salib, P. \& Rupert, D.J. (2007). Merging qualitative and quantitative data in mixed methods research: How to and why not. Ecological and Environmental Anthropology, 3(1), 19-28.

Dutton, J.E. (1993). The making of organizational opportunities: An interpretive pathway to organizational change, In L. L. Cummings, \& B. M. Staw (Eds.), Research in organizational behavior (pp. 195-226). Greenwich, CT: JAI Press. 
Edmondson, A.C. (1999). Psychological safety and learning behavior in work teams. Administrative Science Quarterly, 44(2), 350-383.

Garsen, D.G. (2002). Guide to writing empirical papers, thesis and dissertation. New York: Marcel Dekker, Inc.

Gay, L.R., Geoffrey, E.M. \& Airasian, P. (2006). Educational research: Competencies for analysis and application, New Jersey, Pearson Education.

Ghosh, M. and Sobek, D.K. (2006, May). A test of the design rules in health care. Paper presented at the Industrial Engineering Research conference, Orlanda, FL.

Goldstein F.C., and Levin H.S. (1987). Disorders of reasoning and problem-solving ability. In M. Meier, A. Benton, \& L. Diller (Eds.), Neuropsychological rehabilitation. London: Taylor \& Francis Group.

Hackman, J.R., \& Wageman, R. (1995). Total quality management: Empirical, conceptual, and practical issues. Administrative Science Quarterly, 40(2), 309342.

Hillsden, I., \& Fenton, G. (2006). Improving practice and patient safety through a medication systems review. Quality in Primary Care, 14 (1), 33-40.

Huq, Z., \& Martin, T.N. (2000). Workforce cultural factors in TQM/CQI implementation in hospitals. Health Care Management Review, 25(3), 80-93.

Institute of Medicine. (1999). To Err is Human: Building a Safer Health System. A Report of the Institute of Medicine, Washington, DC.

Institute of Medicine. (2005). Building a better delivery system: a new engineering/heath care partnership. A Report of the Institute of Medicine, Washington, DC.

Institute of Medicine. (2006). Preventing medication errors: quality chasm series. A Report of the Institute of Medicine, Washington, DC.

Jimmerson, C., Weber, D., Sobek, D.K. (2005). Reducing waste and errors: Piloting lean principles at IHC. Joint Commission Journal on Quality and Safety, 31(5), 249-257. 
Johnson, S. (1998). What's in a representation, why do we care, and what does it mean? Examining evidence from psychology. Automation in Construction, 8, 15-24.

Lei, D., Hitt, M. A., \& Bettis, R. (1996). Dynamic core competencies through metalearning and strategic context. Journal of Management, 22 (4), 549-569.

Lewis, J.W. (2006). Cortical networks related to human use of tools. The Neuroscientist, 12(3), 211-231.

Linderman, K. Scroeder, R.G., Zaheer, S., \& Choo, A.S. (2003). Six sigma: A goaltheoretic perspective. Journal of Operations Management, 21(2), 193-203.

Mason, C. H., \& Perreault, W. D. (1991). Collinearity, power, and interpretation of multiple regression analysis. Journal of Marketing Research, 23, 268-280.

McFadden, K.L., Stock, G.N, \& Gowen, C.R. (2006a). Exploring strategies for reducing hospital errors. Journal of Healthcare Management, 51(2), 123-136.

McFadden, K.L., Towell, E.R., \& Stock, Gregory N. (2006b). Implementation of patient safety initiatives in US hospitals. International Journal of Operations and Production Management, 26(3), 326-347.

Mazur, L.M. (2008). The Study of Errors, Expectations, and Skills for Medication Delivery Improvement, Ph.D. Dissertation submitted to Industrial Engineering Department, Montana State University.

Mazur, L.M. \& Chen, S.J. (2007, April). Improving medication delivery using systems engineering approach. Proceedings of Industrial Engineering Research Conference, Nashville, Tennessee, 2007.

Mazur, L.M., \& Chen, S.J. (2008a). Understanding and reducing waste due to medication errors via systems mapping and analysis. Health Care Management Science, 11(1), 55-65.

Mazur, L.M. \& Chen, S.J. (2008b). An empirical study for medication delivery improvement based on healthcare professionals' perceptions of medication delivery system. To appear in Health Care Management Science. 
Miles, M.B., \& Huberman, A.M. (1994). Qualitative data analysis: an expanded sourcebook. Sage, Thousand Oaks, CA.

Mohr, J.J., Batalden, P \& Barach, P. (2004). Integrating patient safety into the clinical microsystem. Quality and Safety in Health Care, 13(6), 34-38.

Monden Y. (1993). The Toyota Production System. Institute of Industrial Engineers, Atlanta.

National Patient Safety Foundation. (2004). Five years after to err is human: a look at the patient safety landscape. Focus on Patient Safety Newsletter, 7(3), 1-3.

Nembharth, I.M. and Edmondson, A.M. (2006). Making it safe: The effects of leader inclusiveness and professional status on psychological safety and improvement efforts in health care teams. Journal of Organizational Behavior, 27, 941-966.

Ohno T. (1988). The Toyota Production System: Beyond large-scale production. Productivity Press, Portland, OR.

Pelled, L.H., Eisenhardt, K.M., \& Xin, K.R. (1999). Exploring the black box: An analysis of work group diversity, conflict, and performance. Administrative Science Quarterly, 44 (1), 1-28.

Peschl, M. \& Stary, C. (1998). The role of cognitive modeling for user interface design representations. Minds and Machines, 8, 203-236.

Reason, J., 2004. Beyond the organizational accident: the need for 'error wisdom' on the frontline, Quality and Safety in Health Care, 13(6), 28-33.

Repenning, N.P., and Sterman, J.D. (2002). Capability traps and self-confirming attribution errors in the dynamics of process improvement. Administrative Science Quarterly, 47(2), 265-295.

Robinson, J.P., Shaver, P.R., \& Wrightsman, L.S. (1991). Criteria for scale selection and evaluation: Measures of personality and social psychological attitudes. San Diego: Academic Press.

Shingo S. (1989). A study of the Toyota Production System from an industrial engineering viewpoint. Productivity Press, Portland, OR, 1989. 
Sobek, D.K., \& Jimmerson, C. (2003). Applying the Toyota Production System to a hospital pharmacy. Paper Presented at the Industrial Engineering Research Conference, Portland, Oregon.

Sobek, D.K., and Jimmerson, C. (2004). A3 reports: Tool for process improvement. Paper Presented at the Industrial Engineering Research Conference, Houston, Texas.

Sobek, D.K., and Jimmerson, C. (2006). A3 reports: Tool for organizational transformation. Paper presented at the Industrial Engineering Research Conference, Orlanda, FL, 2006.

Spear, S.J. (2005). Fixing healthcare from the inside, today. Harvard Business Review, 83(9), 78-91.

Staver, J.R. (1986). The effects of problem format, number of independent variables, and their interaction on student performance on a control of variable reasoning problem, Journal of Research in Science Teaching, 23(6), 533-542.

Thompson, D.N., Wolf, G.A., \& Spear, S.J. (2003). Driving improvement in patient care. Journal of Nursing Administration, 33(11), 585-595.

Tucker, A.L., Edmondson, A.C. (2002). Managing routine exception: a model of nurse problem solving behavior. Advances in Healthcare Management, 3, 87-113.

Tucker, A.L., Edmondson, A.C. (2003). Why hospitals don't learn from failures: organizational and psychological dynamics that inhibit system change. California Management Review, 45(2), 55-72.

Uribe, C.L., Schweikhart, S.B., Pathak, D.S., Dow, M., \& Marsh, G.B. (2002). Perceived barriers to medication error reporting: An explanatory investigation. Journal of Healthcare Management, 47(4), 263-280.

Zbaracki, M. J. (1998). The rhetoric and reality of total quality management. Administrative Science Quarterly, 43(3), 602-636. 


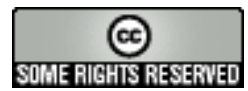

Article's contents are provided on a Attribution-Non Commercial 3.0 Creative commons license. Readers are allowed to copy, distribute and communicate article's contents, provided the author's and Journal of Industrial Engineering and Management's names are included. It must not be used for commercial purposes. To see the complete license contents, please visit http://creativecommons.org/licenses/by-nc/3.0/. 